\title{
Shear localization of fcc high-entropy alloys
}

\author{
Marc A. Meyers ${ }^{1, *}$, Zezhou $\mathrm{Li}^{1}$, Shiteng Zhao ${ }^{1}$, Bingfeng Wang ${ }^{2}$, Yong Liu ${ }^{2}$, Peter K. Liaw ${ }^{3}$ \\ ${ }^{1}$ University of California, San Diego, La Jolla, California, USA \\ ${ }^{2}$ Central South University, Changsha, Hunan, P. R. China \\ ${ }^{3}$ University of Tennessee, Knoxville, USA
}

\begin{abstract}
Dynamic behavior of the single phase (fec) $\mathrm{Al}_{0.3} \mathrm{CoCrFeNi}$ and $\mathrm{CoCrFeMnNi}$ high-entropy alloys (HEAs) was examined. The combination of multiple strengthening mechanisms such as solid solution hardening, cutting forest dislocation, as well as mechanical nano-twinning leads to a high work-hardening rate, compared with conventional alloys. The resistance to shear localization was studied by dynamicallyloading hat-shaped specimens to induce forced shear localization. However, no adiabatic shear band could be observed for A10.3CoCrFeNi HEA at a large shear strain 1.1 . Additionally, shear localization of the $\mathrm{CoCrFeMnNi} \mathrm{HEA} \mathrm{was} \mathrm{only} \mathrm{found} \mathrm{at} \mathrm{an} \mathrm{even} \mathrm{larger} \mathrm{shear} \mathrm{strain} \sim 7$ under dynamic compression. It is therefore proposed that the combination of the excellent strain-hardening ability and modest thermal softening of these two kinds of high-entropy alloys gives rise to remarkable resistance to shear localization, which makes HEAs excellent candidates for impact resistance applications.
\end{abstract}

\section{Introduction}

Adiabatic shear localization is recognized as an important failure mechanism of materials and is produced by the temperature rise in a narrow region, especially formed under high strain-rate deformation, when the deformation time is lower than the heat diffusion time [1]. Cantor et al. [2] developed the $\mathrm{CrMnFeCoNi} \mathrm{HEA}$ with the single face-centered-cubic (fcc) phase and therefore this alloy is also known as the Cantor alloy. Recently, Gludovatz et al. [3] found that this $\mathrm{CrMnFeCoNi}$ HEA achieved remarkable damagetolerance with a tensile strength above $1 \mathrm{GPa}$ and fracture toughness exceeding $200 \mathrm{MPa} \cdot \mathrm{m}^{1 / 2}$. Furthermore, its mechanical properties improved at cryogenic temperatures due to the transition of deformation mechanism from planar dislocation slip to mechanical nanotwinning. This excellent strainhardening ability at cryogenic temperature $(77 \mathrm{~K})$ results in outstanding combinations of strength and ductility of the Cantor alloy. However, dynamic properties of fcc (face-centered-cubic) high-entropy alloys, especially shear localization, are still unexplored.

\section{Experimental procedures}

Dynamic compression tests were performed using a split-Hopkinson pressure bar (SHPB) [4]. The dynamic mechanical properties and shear deformation were measured using cylindrical and hat-shaped specimens, respectively. Hat-shaped specimens with the stopper rings were used to generate high shear strain in the "forced" localized region. The deformed microstructure was polished and etched by dilute aqua regia solution before microstructural characterization. The original and deformed microstructures were examined in a Phillips XL30 scanning electron microscope (SEM). The transmission electron microscopy (TEM) samples were characterized by a FEI Tecnai $\mathrm{G}^{2}$ Polara TEM operating at $200 \mathrm{kV}$.

\section{Results and discussion}

$\mathrm{Al}_{0,3} \mathrm{CoCrFeNi}$ HEA with high densities of annealing twins [5]. The presence of annealing twins is inversely related to the stacking fault energy which is very low in high-entropy alloys [6]. The formation of annealing twins can be achieved by grain growth, grain encounter, stacking errors, and stacking-fault packets at migration boundaries during annealing process. Fig. 1(b) shows coarse-grained $\mathrm{CrMnFeCoNi}$ HEA with average grain size about $10 \mu \mathrm{m}$. These two kinds of single phase (fcc) high-entropy alloys were subjected to dynamic loading to examine their dynamic properties, such as strength, and deformation mechanisms, especially on shear localization.

The dynamic behavior of a single phase (fcc) $\mathrm{Al}_{0.3} \mathrm{CrFeCoNi}$ HEA was investigated using a combination of Hopkinson bar experiments, constitutive equations and forced shear localization by Li et al. [5].

Corresponding author: mameyers@eng.ucsd.edu 

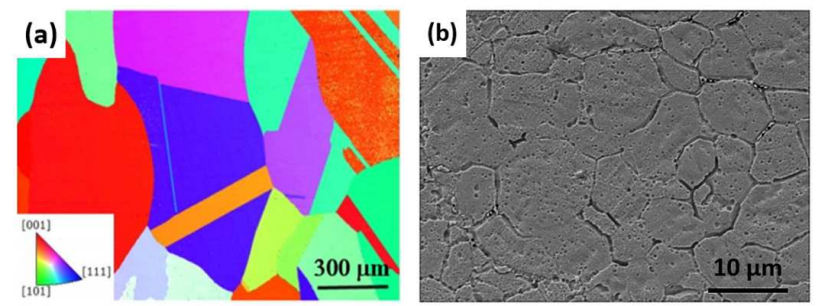

Fig. 1. Initial microstructure of (a) $\mathrm{Al}_{0.3} \mathrm{CoCrFeNi}$ HEA (Electron backscattered diffraction-inverse pole figure) and (b) CrMnFeCoNi HEA (Scanning electron microscopy image) [5].

Fig. 1(a) shows the initial microstructure of The strain-hardening rate of this alloy (about $1000 \mathrm{MPa}$ at a true compressive strain $\sim 0.2$ ) is significantly higher than a $\mathrm{CG}$ pure $\mathrm{Al}$ and retained in the dynamic regime. The combination of multiple strengthening mechanisms such as solid-solution hardening, forest dislocation hardening (Figs. 2(a) and 2(b)), as well as mechanical twinning (Figs. 2(c)) leads to a high work-hardening rate in this alloy shown in Fig. 2(d), which is significantly larger than that for pure aluminum. The resistance to shear localization of this alloy was studied by dynamicallyloading hat-shaped specimens (Fig. 2(e)) to induce forced shear localization. However, no adiabatic shear band could be observed at a shear strain $\sim 1.1$ as depicted in Fig. 2(f). Fig. 2(g) shows the formation of profuse mechanical twins near the inserted tip in the hat-shaped specimen, indicating twinning-induced continuous strain-hardening, which suppresses shear localization in competition with the thermal softening effect.
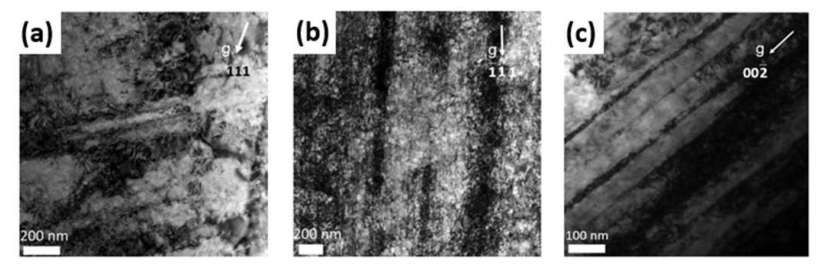

(d)
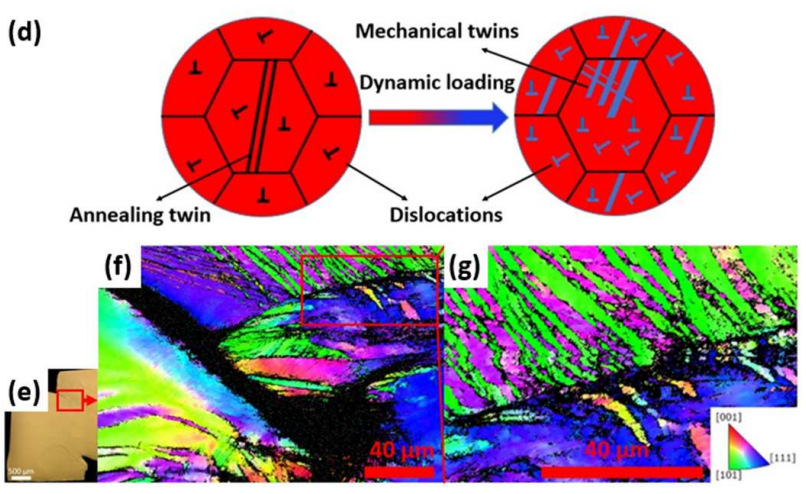

Fig. 2. TEM bright-field images of the deformed samples at the strain-rates of (a) $10^{-4} \mathrm{~s}^{-1}$; (b) and (c) $1800 \mathrm{~s}^{-1}$. (d) Schematic sketches showing the deformation mechanisms of the $\mathrm{Al}_{0.3} \mathrm{CrFeCoNi} \mathrm{HEA}$ under dynamic loading. (e) Optical microscopy image of the deformed hat-shaped sample. (f) EBSD image near the deformation tip. (g) EBSD image showing deformation twins near the deformation tip [5].

Dynamic loading of a series of hat-shaped specimens using stopper rings to control shear displacements was conducted to obtain the critical shear strain for shear localization of the CrMnFeCoNi HEA. Fig. 3(a) demonstrates that only the specimen with a high shear strain of $\sim 7$ develops the shear band. The temperature inside the shear band can rise to the recrystallization temperature ( $\sim 0.4 T_{\text {melting }}$ ); its melting temperature being $1553 \mathrm{~K}$. Fig. 3(b) shows the formation of a narrow shear band with a width $\sim 10 \mu \mathrm{m}$. The microvoids resulting from residual porosity in the spark plasma sintering (SPS) process of this alloy can easily nucleate and propagate cracks along grain boundaries, leading to the separation of particles under dynamic impact. However, this does not affect the shear-localization zone.
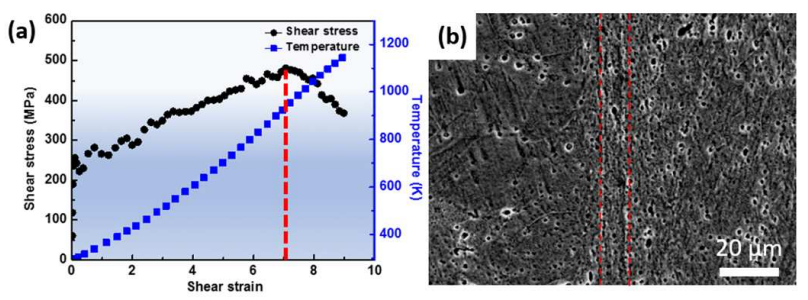

Fig. 3. (a) Shear stress vs. shear strain and temperature evolution of the shear band of the CrMnFeCoNi HEA; (b) scanning electron microscope (SEM) image showing the width of shear band is about $10 \mu \mathrm{m}$.

Figs. 4(a) shows the formation of nanostructured grains inside the shear band of CrMnFeCoNi HEA. The evolution of plastic deformation, coupled with temperature rise as described in Fig. 3(a), leads to the formation of a dislocated/twinned microstructure that breaks up the initial coarse-grained grains into small regions. Recrystallization twins were observed in Fig. 4(b) inside the shear band and are attributed to the dynamic recrystallization process in $\mathrm{CrMnFeCoNi} \mathrm{HEA}$ (with low stacking-fault energy $\sim 20 \mathrm{~mJ} / \mathrm{m} 2$ [6]). The elongated grains are proposed to be the first stage of severe shear deformation; they subsequently break up into small ultrafine-grained grains and rotate to the equiaxed configuration according to the rotational dynamic recrystallization mechanism [1].
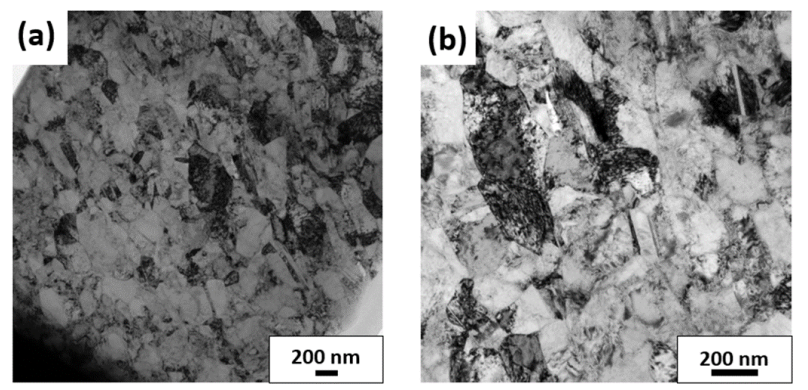

Fig. 4. Transmission electron microscopy images of (a) microstructure inside the shear band in CrMnFeCoNi HEA; (b) recrystallized nanotwins inside the nanostructured and equiaxed grains formed by the rotational dynamic recrystallization mechanism.

Fig. 5(a) shows excellent work-hardening of $\mathrm{Al}_{0.3} \mathrm{CoCrFeNi}$ and $\mathrm{CoCrFeMnNi}$ HEAs under high strain-rate deformation. To reveal the competition mechanisms of strain-hardening effect and thermal softening effect before shear localization, Staker [7] proposed an expression for critical shear strain for shear 
localization (neglecting the effect of strain-rate hardening):

$$
\gamma_{c}=\frac{\rho C_{p} n}{-\frac{\partial \tau}{\partial T}}
$$

where $\rho$ is the density, $C_{p}$ is the specific heat capacity, $n$ is the strain-hardening power index for the constitutive equation ( $\tau=\tau_{0}+K \gamma^{n}$, where $\tau_{0}$ is the yield stress and $K$ is the constant), and the $\frac{\partial \tau}{\partial T}$ term is the thermalsoftening parameter. From Eqn. (1), the value of $\rho C_{p} n$ can be regarded as the hardening component, while the $\frac{\partial \tau}{\partial T}$ is the competitive softening counterpart.

Fig. 5(d) describes the experimental and predicted critical shear strains for shear localization for different materials. All of experimental results agree well with the predicted values. The value of predicted critical shear strain for shear localization of $\mathrm{Al}_{0.3} \mathrm{CoCrFeNi} \mathrm{HEA}$ is $\sim 3.9$ but it still needs elaborate experimental confirmation. The CrMnFeCoNi HEA shows the most remarkable resistance to shear localization, among 7 metals and alloys as depicted in Fig. 5(d); this is attributed to excellent strain-hardening ability as shown in Fig. 5(b) and small thermal softening effect as shown in Fig. 5(c). Fig. 5(b) shows that $\mathrm{Cu}$ has the highest $\rho \mathrm{Cpn}$ value. The value of $\rho \mathrm{Cpn}$ value for $\mathrm{CrMnFeCoNi}$ HEA is about $70 \%$ of that of $\mathrm{Cu}$ and it is slightly higher than that of Ti. The fcc $\mathrm{Cu}, \mathrm{Al}_{0.3} \mathrm{CoCrFeNi}$ HEA, and Cantor alloy all show excellent work hardening ability, which is due to a common strengthening mechanism, cutting forest dislocations. In addition, Fig. 5(c) shows that the Cantor alloy has the smallest thermal softening effect in the temperatures ranging from $200 \mathrm{~K}$ to $1000 \mathrm{~K}$, in comparison with titanium, Ti-6Al-4V alloy, AISI 1006 steel, copper, brass and $\mathrm{Al}_{0.3} \mathrm{CoCrFeNi} \mathrm{HEA}[5,8-$ 12]. Tsai et al. [13] found that interaction energy (which is the excess free energy that arises when two unlike atoms bond with each other) of $\mathrm{Ni}$ element in $\mathrm{CrMn} 0.5 \mathrm{FeCoNi} \mathrm{HEA}$ is higher than that in $\mathrm{Cr}-\mathrm{Fe}-\mathrm{Ni}$ alloy. This leads to a sluggish diffusion effect, and indicates that it needs higher thermal energy to break-up metallic bonds in HEAs than conventional alloys. Thus, the small thermal softening effect of the CrMnFeCoNi HEA can also promote its resistance to shear localization.

\section{Conclusions}

In summary, the resistance to shear localization was studied by dynamically-loading hat-shaped specimens to induce forced shear localization. However, no adiabatic shear band could be observed for $\mathrm{Al}_{0.3} \mathrm{CoCrFeNi} \mathrm{HEA}$ at a large shear strain $\sim 1.1$. Additionally, shear localization of the CoCrFeMnNi HEA was only found at an even larger shear strain $\sim 7$ under dynamic compression. It is therefore proposed that the combination of the excellent strain-hardening ability and modest thermal softening gives rise to remarkable resistance to shear localization, which makes HEAs an excellent candidate for impact resistance applications. Dynamic properties of various high-entropy alloys still need to be explored for future structural applications.
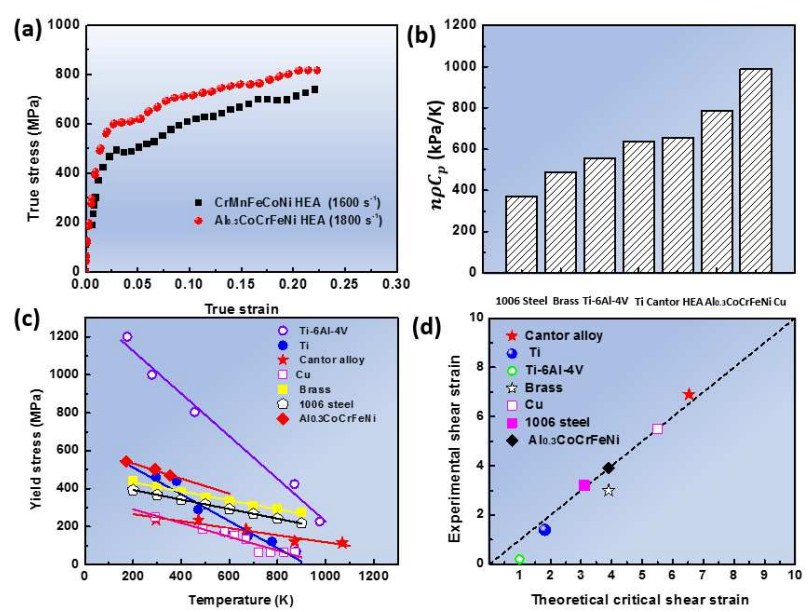

Fig. 5. (a) Mechanical response of $\mathrm{Al} 0.3 \mathrm{CoCrFeNi} \mathrm{HEA}$ and the Cantor alloy under high strain-rates; (b) the value of $\rho C_{p} n$ for pure Ti [8], Ti-6Al-4V alloy [9], 1006-Steel [10], Copper [10], Brass [10], Al0.3CoCrFeNi HEA [5] and the Cantor alloy; (c) thermal-softening effect of different materials [5,812]; (d) predicted and experimental critical shear strain for shear localization [5,8-12].

\section{References}

1. M.A. Meyers, V.F. Nesterenko, J.C. LaSalvia, Q. Xue, Mater. Sci. Eng. A 317 204-225 (2001)

2. B. Cantor, I.T.H. Chang, P. Knight, A.J.B. Vincent, Mater. Sci. Eng. A 375-377 213-218 (2004)

3. B. Gludovatz, A. Hohenwarter, D. Catoor, E.H. Chang, E.P. George, R.O. Ritchie, Science. 345 (2014) 1153-1158

4. M.A. Meyers, Dynamic behavior of materials, John Wiley \& Sons, 1994

5. Z. Li, S. Zhao, H. Diao, P. K. Liaw, M.A. Meyers, Sci. Rep. 7:42742 (2016)

6. A.J. Zaddach, C. Niu, C.C. Koch, D.L. Irving, J. Mater. 65 1780-1789 (2013)

7. M.R. Staker, Acta Metall. 29 683-689 (1981).

8. M.A. Meyers, G. Subhash, B.K. Kad, L. Prasad, Mech. Mater. 17 175-193 (1994)

9. Q. Xue, M.A. Meyers, V.F. Nesterenko, Acta Mater. 50 575-596 (2002)

10. U.S. Lindholm, G.R. Johnson, Springer US, 61-79 (1983)

11. B. Gludovatz, E.P. George, R.O. Ritchie, J. Mater. 67 2262-2270 (2015).

12. G. R. Johnson, J. M. Hoegfeldt, U. S. Lindholm, A. Nagy, J. Eng. Mater. Tech. 105 42-47 (1983)

13. K.-Y. Tsai, M.-H. Tsai, J.-W. Yeh, Acta Mater. 61 4887-4897 (2013) 
